\title{
Nanoparticles Modified With Cationic Thiol Surfactant as Efficient Inhibitors for the Corrosion of Carbon Steel
}

\author{
Eid M. S. Azzam ${ }^{1 *}$, Radwa M. Sami ${ }^{2}$, Khalaf M. Alenezi ${ }^{1}$, Hani El Moll ${ }^{1}$, and A. Haque ${ }^{1}$ \\ ${ }^{1}$ University of Ha'il, College of Sciences, Department of Chemistry, 81451 Hai'l, Saudi Arabia \\ ${ }^{2}$ Petrochemicals Department, Egyptian Petroleum Research Institute, Nasr City, 11727 Cairo, Egypt
}

\begin{abstract}
In this work, we report synthesis, characterization and corrosion inhibition properties of cationic thiol surfactant-capped silver (SC-Ag-NPs) and gold (SC-Au-NPs) nanoparticles. SC-Ag-NPs and SC-Au-NPs were characterized using regular techniques include TEM. Corrosion study was carried out using carbon steel (CS) in $3.5 \% \mathrm{NaCl}$ aqueous solution and characterized using multiple electrochemical techniques. Our results suggest that the paint containing SC-Ag-NPs and SCAu-NPs endow efficient corrosion protection to the CS. Especially, SC-Au-NPs based paint form a stronger barrier between the metal and the corrosive ions, leading to better inhibition properties.
\end{abstract}

Keywords : Au-Nanoparticles, Ag-Nanoparticles, Mercapto Surfactant, Coating, C-Steel

Received : 4 January 2021, Accepted : 26 January 2021

\section{Introduction}

Metals are subject of deterioration because of their possible corrosion caused by reaction with environment. Salt water is one of the sources that may attack a metal provoking its oxidation. However, corrosion inhibition process is considered as a key solution that can be achieved either using deposition of passive films or active coating on the metals [1-6]. The efficacy of such barriers depends significantly on the properties associated with the films/coating as well as their interaction with the metal surface [7].

Nanoparticles (NPs) are commonly defined as particles with diameter less than $100 \mathrm{~nm}[8,9]$. This miniscule size confer them a high surface to volume ratio, leading to intriguing features and properties. Owing to these, NPs have attracted interest of multidisciplinary researchers. Among others, NPs based on silver (Ag-NPs) and gold (Au-NPs) are particularly interesting [10]. For example, their size can be controlled by judicious selection of the precursor

*E-mail address: eazzamep@yahoo.com

DOI: https://doi.org/10.33961/jecst.2021.00010

This is an open-access article distributed under the terms of the Creative Commons Attribution Non-Commercial License (http://creativecommons.org/licenses/by-nc/4.0)
which permits unrestricted non-commercial use, distribution, and reproduction in any which permits unrestricted non-commercial use, distri
medium, provided the original work is properly cited. materials/reaction conditions, they possess high affinity towards a wide range of organic functionalities and provide site for the formation of self-assembled monolayers $[11,12]$. It has been demonstrated that capping NPs surface using a surfactant-like molecule lowers the free energy and, modulate its reactivity [13].

Ionic liquids (ILs) are new generation of organic compounds with promising corrosion inhibition properties in emerging coating. They come in a vast structural diversity and chemical properties that can be tuned by the judicious selection of cations and anions. Most of their intriguing properties/applications in various discipline of research are related to their low melting $\left(<100^{\circ} \mathrm{C}\right)$ or boiling point $\left(<25^{\circ} \mathrm{C}\right)$, high chemical/thermal stability, benign nature, diverse range of solubility, etc. [14-18]. Intrigued by the promising feature of these two classes of materials, we investigated the corrosion protection property of paint based on newly synthesized surfactantcapped silver (SC-Ag-NPs) and gold (SC-Au-NPs) nanoparticles for the carbon steel. Corrosion inhibition properties was confirmed by multiple electrochemical techniques and the results are discussed herein. 
<smiles></smiles>

$$
\mathrm{R}=\mathrm{C}_{12} \mathrm{H}_{25}
$$

Scheme 1. Chemical formula of the used surfactant, Ndodecyl-4-mercaptopyridine-1-ium bromide (I12).

\section{Experimental}

\subsection{Materials}

2.1.1. Synthesis of N-dodecyl-4-mercaptopyridine1-ium bromide (I12)

Cationic surfactant N-dodecyl-4-mercaptopyridine-1-ium bromide (I12) was prepared following a previously reported procedure (see Scheme 1) [19]. The compound was extensively characterized using FTIR and ${ }^{1} \mathrm{H}$ NMR, and the values were found to be similar, as reported earlier. [20].

\subsubsection{Preparation of Ag-NPs solution}

Ag-NPs colloidal solution was prepared according to a previously reported protocol based on chemical reduction method [21]. In brief, to a $50 \mathrm{~mL}$ of a boiling $\mathrm{AgNO}_{3}$ solution $\left(10^{-3} \mathrm{M}\right), 5 \mathrm{~mL}$ of trisodium citrate solution $(1 \% \mathrm{w} / \mathrm{v})$ was added dropwise while maintaining vigorous mixing. The mixture was heated until a pale yellow color appeared and the stirring was continued until the room temperature is reached [22].

2.1.3. Preparation of Au-NPs solution Au-NPs solution was prepared by the reduction of chloroauric acid $\left(\mathrm{HAuCl}_{4}\right)$ in the presence of sodium borohydride [23, 24]. To a stirred $18.5 \mathrm{~cm}^{3}$ water was added $0.5 \mathrm{~cm}^{3}$ of a $10^{-2} \mathrm{M}$ tri-sodium citrate solution followed by the addition of $0.5 \mathrm{~cm}^{3}$ of a $10^{-3} \mathrm{~cm} 3$ chloroauric acid solution. The temperature of the mixture was cooled using an ice bath and $0.5 \mathrm{~cm}^{3}$ of a $0.1 \mathrm{M}$ sodium borohydride solution was slowly added. The mixture was stirred until the observation of an orange color.

2.1.4. Preparation of the SC-Ag-NPs and SCAu-NPs

To a $20 \mathrm{~cm}^{3}$ of silver or gold nanoparticles solution was added a $5 \mathrm{~cm}^{3}$ solution of a saturated surfactant (prepared in deionized water). The mixture was stirred effectively for $24 \mathrm{~h}$ until it turns colorless [25].

2.1.5. Preparation of the SC-Ag-NPs and SC-AuNPs based paints

Table 1 shows the composition of the paint that is constituted of a mixture of butanol, dibutyl phthalate, $\mathrm{TiO}_{2}$ and talc. The paint was based on coconut oil (short oil) alkyd resin and prepared by stirring the nitrocellulose and the thinner for $30 \mathrm{~min}$ followed by the addition of short oil alkyd resin. The mixture was stirred for additional 20 min before adding SC-AgNPs or SC-Au-NPs and other constituents.

\subsubsection{Carbon steel coating}

The metallic substrate (Carbon steel, CS) sheets of the size $2.0 \times 5.0 \mathrm{~cm}$ having surface area $2.0 \mathrm{~cm}^{2}$ was selected for the corrosion inhibition studies. Prior to use, it was polished, cleaned and washed with solvents very well to remove any dirt or oxidized surfaces, as described in the literature [26]. Paints without (A, Table 2) with or SC-Ag-NPs and SC-AuNPs (B-G, Table 2) were used for the coating and

Table 1. Chemical composition of the paint

\begin{tabular}{ccc}
\hline \hline Materials & Formula or composition & Mass percent (\%) \\
\hline Resin & Short oil alkyd resin & 19 \\
Inorganic pigments & $\mathrm{TiO}_{2}$ & 2 \\
Talc & $\mathrm{Mg}_{3} \mathrm{Si}_{4} \mathrm{O}_{10}(\mathrm{OH})_{2}$ & 15 \\
Dibutyl phthalate & $\mathrm{C}_{16} \mathrm{H}_{22} \mathrm{O}_{4}$ & 15 \\
Butanol & $\mathrm{C}_{4} \mathrm{H}_{9} \mathrm{OH}$ & 2 \\
Nitrocellulose & $\mathrm{C}_{6} \mathrm{H}_{7}\left(\mathrm{NO}_{2}\right)_{3} \mathrm{O}_{5}$ & 4 \\
Solvent & Thinner & 15 \\
\hline
\end{tabular}


Table 2. Modified and unmodified (blank) paint compositions (in grams).

\begin{tabular}{ccccccccc}
\hline \hline Paint code & Nitrocellulose & Butanol & Thinner & Dibutyl phthalate & Resin & SC-NPs & Talc & $\mathrm{TiO}_{2}$ \\
\hline A (Blank) & 2.5 & 0.3 & 6.14 & 1.5 & 3.8 & - & 3 & 1.5 \\
B & 2.5 & 0.3 & 6.14 & 1.5 & 3.8 & 0.2 & 3 & 1.5 \\
C & 2.5 & 0.3 & 6.14 & 1.5 & 3.8 & 0.4 & 3 & 1.5 \\
D & 2.5 & 0.3 & 6.14 & 1.5 & 3.8 & 0.6 & 3 & 1.5 \\
E & 2.5 & 0.3 & 6.14 & 1.5 & 3.8 & 0.8 & 3 & 1.5 \\
F & 2.5 & 0.3 & 6.14 & 1.5 & 3.8 & 1.0 & 3 & 1.5 \\
G & 2.5 & 0.3 & 6.14 & 1.5 & 3.8 & 2.0 & 3 & 1.5 \\
\hline
\end{tabular}

dried at $40^{\circ} \mathrm{C}$ for $72 \mathrm{~h}$.

\subsubsection{Preparation of the corrosive medium}

An aqueous solution of $3.5 \%$ sodium chloride was prepared by dissolving $3.5 \mathrm{~g}$ of $\mathrm{NaCl}$ in $100 \mathrm{~g}$ of double distilled water as corrosive solution. The corrosion inhibition efficiency of carbon steel electrode with unmodified paint (without SC-Ag-NPs or SCAu-NPs) and modified paint (containing different amounts of SC-Ag-NPs or SC-Au-NPs) was measured by three different technique (potentiodynamic polarization, electrochemical impedance spectroscopy measurements and the salt spray test).

\subsection{Electrochemical measurements}

\subsubsection{Potentidynamic polarization}

Potentiodynamic polarization measurements were performed using a conventional platinum (counter electrode), saturated calomel (reference electrode) and carbon steel (working electrode) system. All electrochemical measurements curves were recorded using a Voltalab 40 Potentiostat PGZ 301 and a personal computer with Voltamaster 4 software. The working electrode was immersed in corrosive solution at open circuit potential for 30 min until a steady state was reached. Potentiodynamic polarization measurements were obtained by changing the electrode potential automatically from -1400 to $-200 \mathrm{mV}$ $v s$. SCE with a scan rate of $2 \mathrm{mV}^{-1}{ }^{-1}$ at $30^{\circ} \mathrm{C}$. The reproducibility was checked by repeating each measurement, at least three times.

2.2.2 Electrochemical impedance spectroscopy (EIS)

The alternating voltage perturbation imposed on the cell is ( $5 \mathrm{mV}$ peak by peak) was imposed on the cell over the frequency range of from $100 \mathrm{kHz}$ to

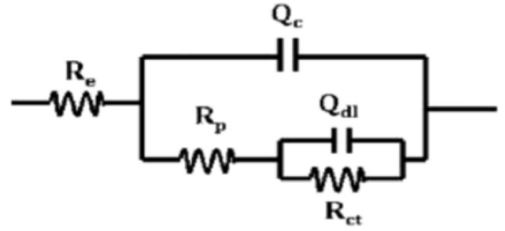

Fig. 1. The electrical equivalent circuit model.

$50 \mathrm{mHz}$. The EIS spectra from attached films were analyzed using nonlinear least squares fitting (with ZSimWin) to an R [Q[R[QR]]] model circuit as illustrated in Fig. $1[\mathrm{Q}=$ constant phase element]. The circuit in Fig.1, which used for coated metals with a conducting pathway (or pore) modeled as a resistance in series with a parallel RC combination at the metal surface to clarify the electrochemical reaction there (or more recently RQ to represent non-ideal behavior). The capacitance (or Q) of the coating materials is arranged in parallel with this combination and short circuits the whole combination at high frequency. EIS spectra from coating films which should in principle be fitted $\mathrm{R}[\mathrm{C}[\mathrm{R}[\mathrm{CR}]]$, however it is actually analyzed with the circuit R [Q[R [QR]]] (Fig. 1) which indicate better fit.

\subsubsection{Salt spray test}

It is an accelerated corrosion test that produces a corrosive attack to the coated samples in order to predict its suitability in use as a protective finish. In this test, appearance of corrosion products is evaluated after regular interval, which depends on the corrosion resistance of the coating. The coated specimens were subjected to diagonal scratches with the help of a sharp knife in order to expose the base metal to a continuous salt fog chamber of $3.5 \mathrm{wt} \% \mathrm{NaCl}$ solution. 
Measurements were obtained using salt spray chamber model SF/450 (England) at $35^{\circ} \mathrm{C}$.

2.2.4. Transmission electron microscope (TEM)

Size of the NPs were determined using Jeol JeM 2100 (Japan) TEM machine.

\section{Results and Discussion}

\subsection{Structural characterization of SC-Ag-NPs and} SC-Au-NPs

In this work we used the FTIR spectrum to confirm the formation of SC-Ag-NPs/SC-Au-NPs. Comparing, the FTIR of SC-Ag-NPs/SC-Au-NPs with that of I12 compound clearly indicates the coating of surfactant on the nanoparticles. The adsorption bands observed are as follow: 2956.59/3038.04 $\mathrm{cm}^{-1}$ (asym $\mathrm{CH}_{2}$ ), 2920/2955.83 $\mathrm{cm}^{-1}$ (sym SH), 2851.15/2853 $\mathrm{cm}^{-1}\left(\mathrm{sym} \mathrm{CH}_{2}\right), 1622.29 / 1622.08 \mathrm{~cm}^{-1}(\mathrm{C}=\mathrm{N})$, $1588.96 / 1588.51 \mathrm{~cm}^{-1}\left(\mathrm{CH}_{2}\right.$ binding $), 1470.90 /$ $1471.75 \mathrm{~cm}^{-1}$ (C=C, Ar), $110.42 / 1109.79 \mathrm{~cm}^{-1}(\mathrm{C}-\mathrm{N})$ and sym (C-S) bands around $716.96 / 715.84 \mathrm{~cm}^{-1}$.

Fig. 2 shows the TEM of the SC-Ag-NPs and SCAu-NPs. Based on the particles size, we conclude that the effective stabilization of the nanoparticles that leads to the formation of SC-Ag-NPs and SC$\mathrm{Au}-\mathrm{NPs}$ with particle size ranging from 10 to $18 \mathrm{~nm}$ [25].

\subsection{Corrosion measurement}

Fig. 3 shows the potentiodynamic responses of CS coated with unmodified (blank) and modified paints
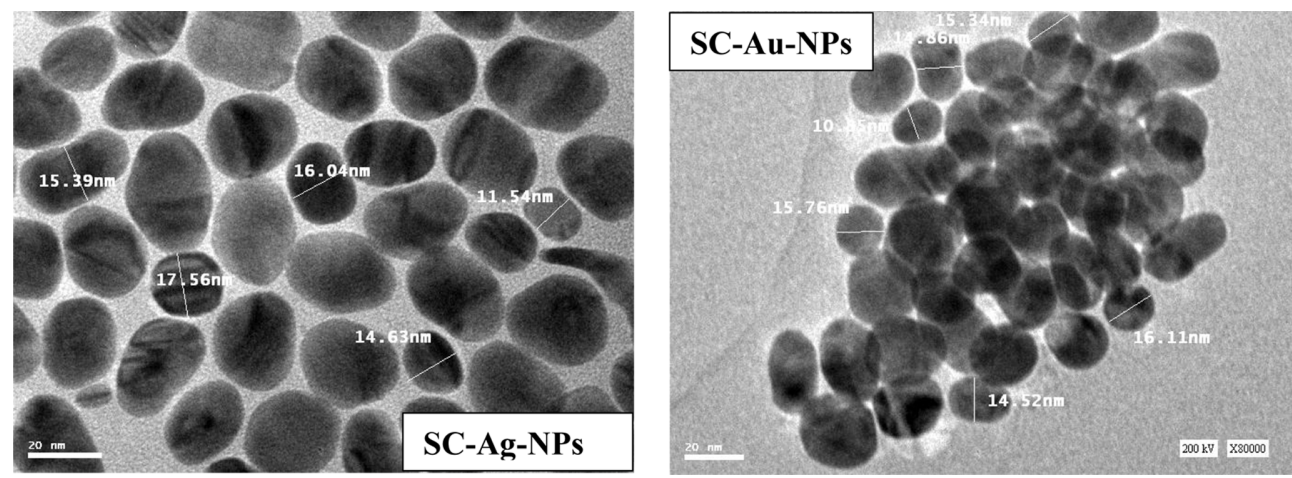

Fig. 2. TEM image of SC-Ag-NPs and SC-Au-NPs.
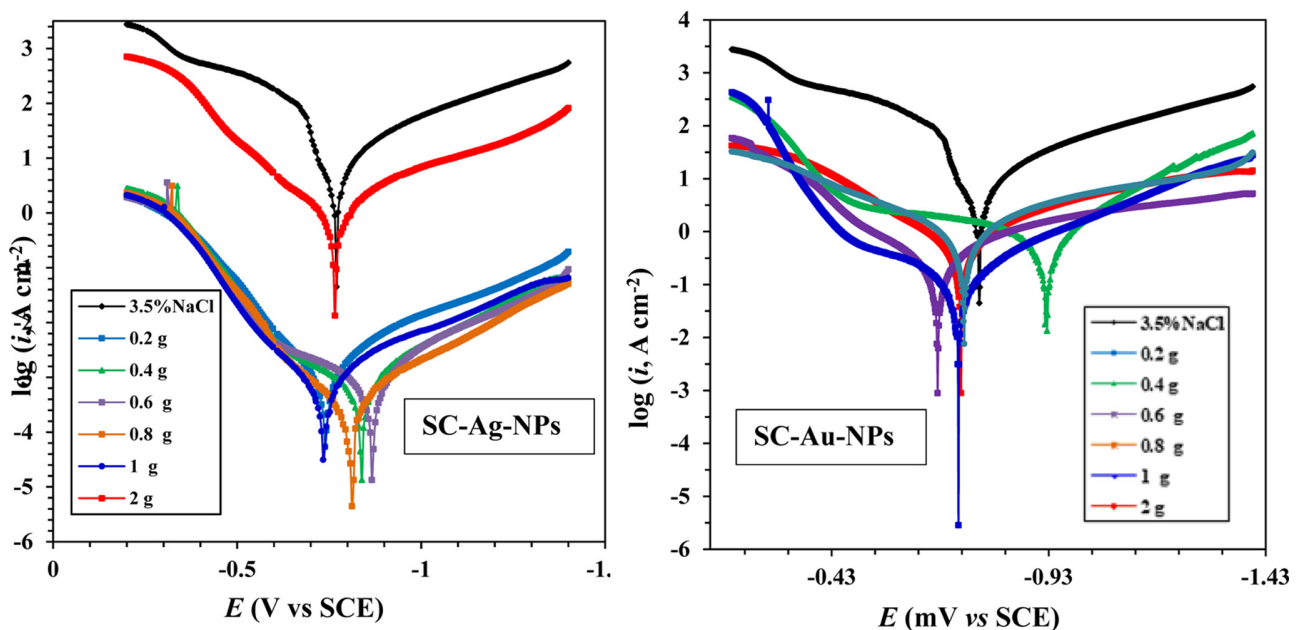

Fig. 3. Potentio dynamic responses of carbon steel modified by paint containing various amounts $(0.2-2 \mathrm{wt} \%)$ of SC-AgNPs and SC-Au-NPs at $30^{\circ} \mathrm{C}$ with scan rate of $1.0 \mathrm{mV}^{-1} \mathrm{~s}^{-1}$. 
Table 3. Potentiodynamic polarization results for carbon steel in $3.5 \mathrm{wt} \% \mathrm{NaCl}$ without and with different concentrations of the SC-Ag-NPs and SC-Au-NPs at $30^{\circ} \mathrm{C}$.

\begin{tabular}{|c|c|c|c|c|c|}
\hline Conc. of SC-NPs & $\begin{array}{c}E_{\text {corr }} \\
(\mathrm{mV})\end{array}$ & $\begin{array}{c}i_{\text {corr }} \\
\left(\mu \mathrm{A} \mathrm{cm}^{-2}\right)\end{array}$ & $\begin{array}{c}\beta_{\mathrm{a}} \\
\left(\mathrm{mV} \operatorname{dec}^{-1}\right)\end{array}$ & $\begin{array}{c}\beta_{\mathrm{c}} \\
\left(\mathrm{mV} \operatorname{dec}^{-1}\right)\end{array}$ & $\begin{array}{l}\eta_{\mathrm{p}} \\
(\%)\end{array}$ \\
\hline Blank & -771.8 & 10.1101 & 107.6 & -295.6 & \\
\hline 0.2 g SC-Ag-NPs & -742.3 & 1.0223 & 170.3 & -188.6 & 89.888329 \\
\hline 0.4 g SC-Ag-NPs & -840 & 0.9548 & 445.3 & -273.3 & 90.55598 \\
\hline $0.6 \mathrm{~g} \mathrm{SC}-\mathrm{Ag}-\mathrm{NPs}$ & -869.1 & 0.8834 & 409.6 & -223.7 & 91.26220314 \\
\hline $0.8 \mathrm{~g} \mathrm{SC}-\mathrm{Ag}-\mathrm{NPs}$ & -812.7 & 0.4614 & 286.7 & -288.8 & 95.43624692 \\
\hline $1.0 \mathrm{~g} \mathrm{SC}-\mathrm{Ag}-\mathrm{NPs}$ & -738.3 & 1.1611 & 217.9 & -319.2 & 88.51544495 \\
\hline $2.0 \mathrm{~g} \mathrm{SC}-\mathrm{Ag}-\mathrm{NPs}$ & -767.8 & 1.6976 & 286.3 & -388.9 & 83.20887034 \\
\hline $0.2 \mathrm{~g} \mathrm{SC}-\mathrm{Au}-\mathrm{NPs}$ & -730.4 & 0.7866 & 295.7 & -358.3 & 92.21966153 \\
\hline $0.4 \mathrm{~g} \mathrm{SC}-\mathrm{Au}-\mathrm{NPs}$ & -927.5 & 0.6784 & 431.1 & -205 & 93.28987844 \\
\hline $0.6 \mathrm{~g} \mathrm{SC}-\mathrm{Au}-\mathrm{NPs}$ & -676.6 & 0.364 & 317.7 & -374 & 96.39963996 \\
\hline $0.8 \mathrm{~g} \mathrm{SC}-\mathrm{Au}-\mathrm{NPs}$ & -724 & 0.1650415 & 442.1 & -285.5 & 98.36755818 \\
\hline $1.0 \mathrm{~g} \mathrm{SC}-\mathrm{Au}-\mathrm{NPs}$ & -737.6 & 1.1162 & 393.2 & -399.5 & 88.9595553 \\
\hline
\end{tabular}

in $3.5 \mathrm{wt} \% \mathrm{NaCl}$ solution. Compared to the blank (i.e. mixed-type inhibitors), the presence of SC-NPs with different concentrations $(0.4,0.6,0.8,1,2 \mathrm{wt} \%)$ shifted the corrosion potential to more negative potentials for cathodic process and more positive potentials for anodic process. However, the shift in $E_{\text {corr }}$ does not follow the same trend while increasing the amount of nanoparticles. Notably, the corrosion current decreased when the increasing amount of NPs (upto 0.8 wt \%) affirming the anti-corrosive property. The electrochemical data obtained from the Tafel plot (such as $E_{\text {corr }}, i_{\text {corr }}, \beta_{a}$ and $\beta_{c}$, Table 3) revealed that the value of $i_{\text {corr }}$ for the electrode painted with unmodified paint was larger than one coated with modified paints. The inhibition efficiency $\left(\eta_{p}\right)$ of the SC-Ag-NPs and SC-Au-NPs can be calculated as $[27,28]$ :

$$
\eta_{p}=\left(\frac{i_{\text {corr }}^{o}-i_{\text {corr }}}{i_{\text {corr }}^{o}}\right) \times 100
$$

Where, $i_{\text {corr }}^{o}$ and $i_{\text {corr }}$ are the corrosion current densities in the presence of unmodified and modified paints, respectively.

Fig. 4 show the relation between $\eta_{p}$ and the amount of SC-NPs in the modified paint. Data in Table 3 show that, $i_{\text {corr }}$ decreases with the increment of the amount of SC-NPs until a value of $0.8 \mathrm{wt} \%$, thereby, causing inhibition of the corrosion. Notably, the $i_{\text {corr }}$ values for SC-Au-NPs is higher than $i_{\text {corr }}$ values for
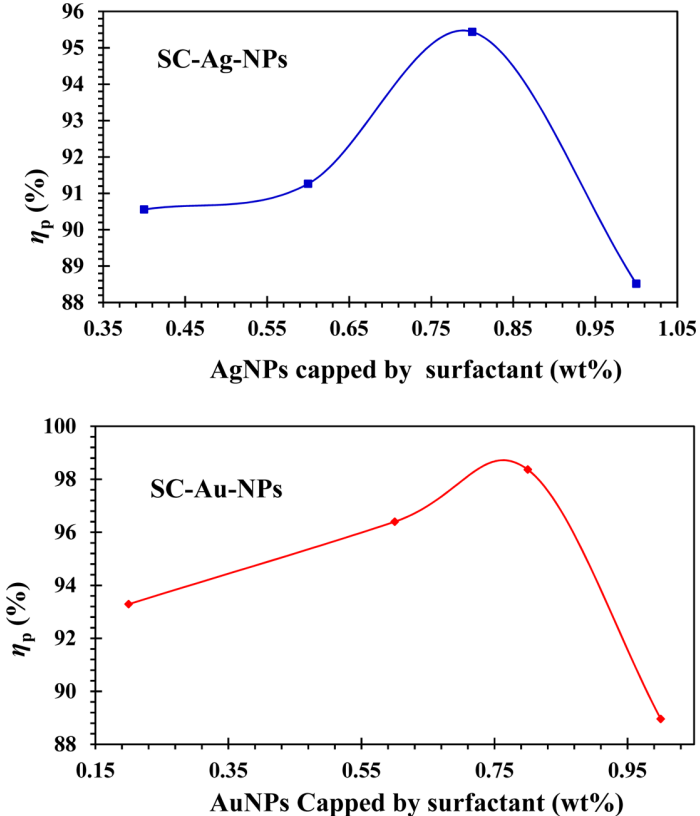

Fig. 4. The relation between $\eta_{\mathrm{p}}$ with the amount of SC-AgNPs and SC-Au-NPs.

SC-Ag-NPs. Therefore, we can deduce that whenever the carbon-steel electrode coated with modified paint is immersed in $3.5 \mathrm{wt} \% \mathrm{NaCl}$ solution, the metal/coated interface exposes to the corrosive agent/ ion $\left(\mathrm{H}_{2} \mathrm{O} / \mathrm{Cl}^{-1}\right)$ which, in normal conditions, reach the 

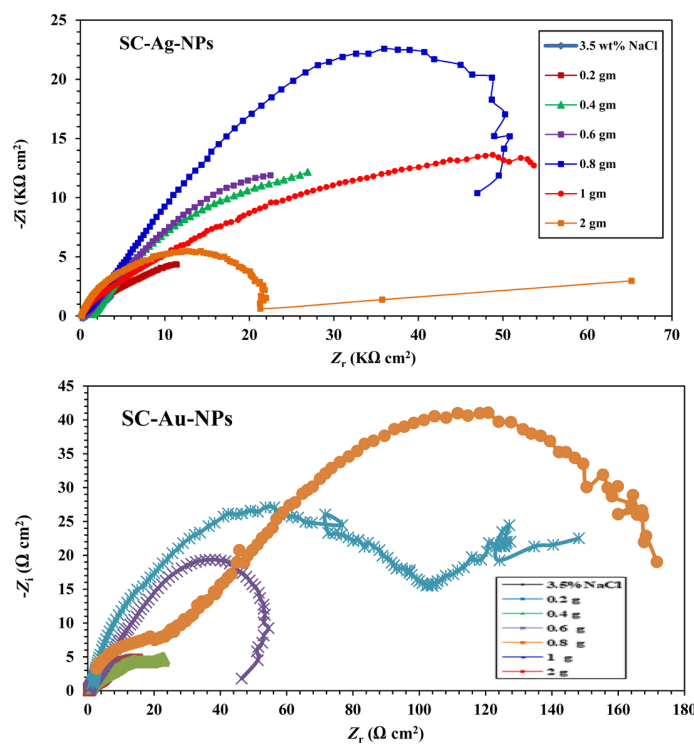

Fig. 5. Nyquist plots coated carbon steel by unmodified and modified paint containing.

SC-Ag-NPs and SC-Ag-NPs with amount (0.2-2 wt \%) and immersed in $3.5 \mathrm{wt} \% \mathrm{NaCl}$ solution

metal through the pores and corroded it. Meanwhile, the modification causes mainly the blockage of the active reaction sites inside the pores and holes. It is worth to note that the increment of the amount of nanoparticles until $0.8 \mathrm{wt} \%$ exhibit better barrier caused by the agglomerations observed between the nanoparticles. Therefore, an excessive amount of SCNPs that can easily agglomerate and convert to micron size, because of a large specific surface area and high surface, decreases the inhibition efficiency. In addition, this agglomeration decrease the NPs diffusion through all the pores to block the inside active sites. Consequently, the corrosive agents of the medium penetrate across the coating and corrode the metal.

The corrosion process was investigated using electrochemical impedance spectroscopic measurements. Fig. 5 represents the Nyquist plots of the coated carbon steel with unmodified and modified paint immersed in $3.5 \mathrm{wt} \% \mathrm{NaCl}$ solution. Notably, the Nyquist plots exhibit a non-perfect semicircle shape indicating that the corrosion process is mainly a charge transfer control [29]. Moreover, comparing to the carbon steel with unmodified paint, the ones containing SC-NPs show larger semicircle diameter. In addition, the diameter of the semicircle increase with the amount of SC-NPs from 0.2 to $2 \mathrm{wt} \%$. This is mainly due to the agglomeration caused by the increase of the NPs grain size. It is also worth to note that the charge transfer resistance $R_{c t}$ increase with the amount of NPs indicating the blockage of the active sites on the metal interface by absorbing the NPs on the holes and pores. This lead to the reduction of the active sites area.

\subsection{Mechanism of the corrosion inhibition}

The experimental impedance spectra uses the appropriate equivalent electric circuits (EECs). Impedance is the total complex resistance when current flow through a circuit made of capacitors, and resistors, or any combination of them [30]. For the used paint, the suggested circuit, called a Randales circuit, is represented in Fig. 1 . Note that $R_{\mathrm{s}}$ is the solution resistance, $R_{\mathrm{e}}$ is the electrolyte resistance, $R_{\mathrm{p}}$ is the coating pore resistance, $Q_{\mathrm{c}}$ and $n_{1}$, respectively, represent the magnitude and exponent of the constant phase element (CPE) of the composite coating and $Q_{\mathrm{dl}}$ and $n_{2}$, respectively, represent the magnitude and exponent of the constant phase element (CPE) of the double layer, which reflect the states of the electrochemical reactions under coating. The impedance of this element $\left(Z_{\mathrm{CPE}}\right)$ is given according to the following equation:

$$
Z_{C P E}=\frac{1}{Q_{o}\left(j \omega_{\max }\right)^{n}}
$$

Where, $Q_{\mathrm{o}}$ is a frequency-independent constant, $\mathrm{j}_{2}$ $=-1, \omega_{\max }=2 \pi f_{\max }, f_{\max }$ is the frequency at which the imaginary component of the impedance is maximal and $\mathrm{n}$ is the exponential coefficient. For $n=0, Z_{\mathrm{CPE}}$ represents a resistance with $\mathrm{R}=Q_{0}{ }^{-1}$, for $n=1$ a capacitance with $\mathrm{C}=Q_{0}$, for $n=0$ a Warburg impedance with $w=Q_{\mathrm{o}}$ and for $n=-1$ an inductive with $\mathrm{L}=Q_{\mathrm{o}}{ }^{-1}$.

The inhibition efficiency, $\left(\eta_{\mathrm{I}}\right)$, of SC-Ag-NPs and $\mathrm{SC}-\mathrm{Au}-\mathrm{NPs}$ calculated from the charge transfer resistance according to the following equation $[31,32]$ :

$$
\eta_{\mathrm{I}}=\left(\frac{R_{\mathrm{ct}}-R_{\mathrm{ct}}^{o}}{R_{\mathrm{ct}}^{o}}\right) \times 100
$$

where $R_{\text {ct }}^{\mathrm{o}}$ and $R_{\mathrm{ct}}$ are charge transfer resistance values obtained for carbon steel electrode in $3.5 \mathrm{wt} \%$ $\mathrm{NaCl}$ solution plated with unmodified and modified paints, respectively.

From the Table 4, the values of $\eta_{\mathrm{I}}$ indicate that the corrosion inhibition efficiency of the painted carbon 
Table 4. The electrochemical kinetic parameters of impedance for carbon steel coated without and with different concentrations of SC-Ag-NPs and SC-Au-NPs in $3.5 \mathrm{wt} \% \mathrm{NaCl}$ at $30^{\circ} \mathrm{C}$

\begin{tabular}{|c|c|c|c|c|c|c|c|c|c|c|}
\hline \multirow[b]{2}{*}{ Additive } & \multirow{2}{*}{$\begin{array}{l}\text { Wt. } \\
(\%)\end{array}$} & \multirow{2}{*}{$\begin{array}{c}R_{\mathrm{p} 1} \\
\left(\mathrm{k} \Omega \mathrm{cm}^{2}\right)\end{array}$} & \multicolumn{2}{|l|}{$Q_{1}$} & \multirow[b]{2}{*}{$\begin{array}{c}R_{\mathrm{p} 2} \\
\left(\mathrm{k} \Omega \mathrm{cm}^{2}\right)\end{array}$} & \multicolumn{2}{|l|}{$Q_{2}$} & \multirow{2}{*}{$\begin{array}{c}W \\
\left(\Omega^{-1} \mathrm{~s}^{\mathrm{n}}\right. \\
\left.\mathrm{cm}^{-2}\right)\end{array}$} & \multirow[b]{2}{*}{$X^{2}$} & \multirow[b]{2}{*}{$\begin{array}{c}\eta \\
(\%)\end{array}$} \\
\hline & & & $\begin{array}{c}Y_{\mathrm{o}} \\
\left(\Omega^{-1} \mathrm{~s}^{\mathrm{n}} \mathrm{cm}^{-2}\right)\end{array}$ & $\mathrm{n}$ & & $\begin{array}{c}Y_{\mathrm{o}} \\
\left(\Omega^{-1} \mathrm{~s}^{\mathrm{n}} \mathrm{cm}^{-2}\right)\end{array}$ & $\mathrm{n}$ & & & \\
\hline- & Blank & 65.0 & $1.53 \mathrm{E}^{-7}$ & 0.90 & 13120 & $1.85 \mathrm{E}^{-5}$ & 0.47 & 0.00068 & 0.102 & - \\
\hline \multirow{5}{*}{ SC-Ag-NPs } & 0.2 & 417.3 & $4.03 \mathrm{E}^{-8}$ & 0.81 & 41258 & $1.54 \mathrm{E}^{-6}$ & 0.57 & - & 0.087 & 84.42 \\
\hline & 0.4 & 712.4 & $1.18 \mathrm{E}^{-8}$ & 0.83 & 74258 & $1.24 \mathrm{E}^{-6}$ & 0.61 & - & 0.089 & 90.88 \\
\hline & 0.6 & 827.8 & $2.27 \mathrm{E}^{-9}$ & 0.78 & 99782 & $1.01 \mathrm{E}^{-7}$ & 0.55 & - & 0.085 & 92.15 \\
\hline & 0.8 & 1417.2 & $1.75 \mathrm{E}^{-9}$ & 0.83 & 145345 & $1.44 \mathrm{E}^{-8}$ & 0.56 & - & 0.083 & 95.41 \\
\hline & 1.0 & 1124.7 & $2.03 \mathrm{E}^{-9}$ & 0.88 & 120457 & $1.72 \mathrm{E}^{-8}$ & 0.55 & - & 0.088 & 94.22 \\
\hline \multirow{5}{*}{ SC-Au-NPs } & 0.2 & 504.9 & $3.99 \mathrm{E}^{-8}$ & 0.77 & 48451 & $1.37 \mathrm{E}^{-6}$ & 0.58 & - & 0.084 & 87.13 \\
\hline & 0.4 & 672.3 & $3.34 \mathrm{E}^{-8}$ & 0.74 & 67458 & $1.12 \mathrm{E}^{-6}$ & 0.56 & - & 0.077 & 90.33 \\
\hline & 0.6 & 1247.5 & $2.44 \mathrm{E}^{-9}$ & 0.85 & 101254 & $1.55 \mathrm{E}^{-8}$ & 0.54 & - & 0.083 & 94.79 \\
\hline & 0.8 & 2347.4 .8 & $0.71 \mathrm{E}^{-9}$ & 0.84 & 167821 & $8.87 \mathrm{E}^{-9}$ & 0.53 & - & 0.074 & 97.23 \\
\hline & 1.0 & 1589.3 & $0.94 \mathrm{E}^{-9}$ & 0.82 & 137485 & $1.02 \mathrm{E}^{-8}$ & 0.55 & - & 0.087 & 95.91 \\
\hline
\end{tabular}

steel electrode in the presence of SC-Ag-NPs and $\mathrm{SC}-\mathrm{Au}-\mathrm{NPs}$ is maximum at $0.8 \mathrm{wt} \%$ and decreases with amounts of SC-NPs.

Double layer capacitances, $C_{\mathrm{dl}}$ is calculated from the following equation:

$$
C_{\mathrm{d} 1}=Q_{\mathrm{d} 1}\left(\omega_{\max }\right)^{n-1}
$$

Where, $\omega_{\max }=2 \pi f_{\max }$ and $f_{\max }$ is the frequency at which the imaginary component of the impedance is maximal. The decrease in $C_{\mathrm{dl}}$ values results from a decrease in local dielectric constant or the effective thickness of the electrical double layer.

From the Table 4 , the values of $C_{\mathrm{dl}}$ decrease with the increment of the amount of SC-NPs. Notaby, the lowest value of $C_{\mathrm{dl}}$ is $0.8 \mathrm{wt} \%$ for Au-NPs. The constant phase element (CPE) was used in the equivalent circuits instead of the ideal electrical capacitance. The obtained results suggest that the nanoparticles are adsorbed at the metal surface [33]. Moreover, the addition of SC-NPs lower the $C_{\mathrm{dl}}$ values. This reduction in capacitance increase the double layer thickness according to the Helmholtz model [34]. This implies close packing of the adsorbed molecules associated with well packed adsorbed of layer and more homogenous adsorbed film of nanoparticles. All these parameters reveal that both silver and gold nanoparticles are effective in preventing corrosion.
Specially, gold nanoparticles are more effective than silver nanoparticles as corrosion inhibition.

\subsection{Adsorption isotherm and standard adsorption free energy}

It is found in our pervious publication that the adsorption of studied N-dodecyl-4-mercaptopyridine-1-ium bromide (I12) surfactant on carbon steel surface obeys the Langmuir adsorption isotherm equation [19]. In addition, the obtained value of $\Delta G^{\mathrm{o}}$ ads, for compound $\mathrm{I} 12$ indicated that the adsorption takes place mainly through the electrostatic interaction between charged inhibitor molecules and the charged metal surface (physisorption and chemisorptions). The results showed that of the $\Delta H^{\mathrm{o}}$ ads value is negative which indicates that the adsorption of on the carbon steel surface is exothermic [19]. Moreover, the $\Delta S_{\text {ads }}^{o}$ values in the presence of the I12 are positive sign, which indicated that, an increase of disorder is due to the adsorption of only one surfactant molecule by desorption of more water molecules [19].

\subsection{Salt spray test}

Results of the salt spray test are depicted in Fig. 5. CS coated with unmodified (blank) and modified paints was subjected carried out for $500 \mathrm{~h}$ at $35^{\circ} \mathrm{C}$. We noted some corrosion products in the scratched 

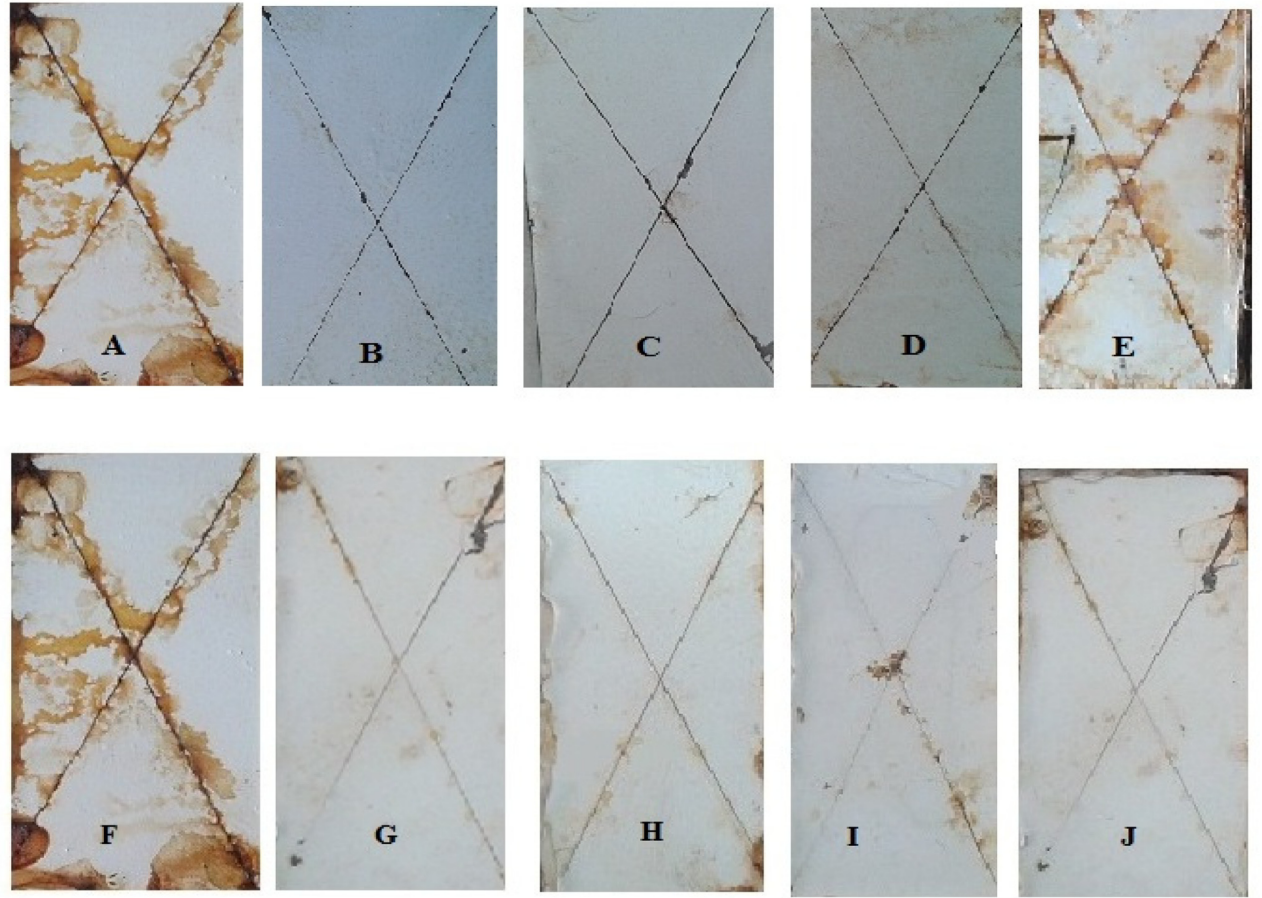

Fig. 6. Salt spray test of steel painted with different paints, (A-E) without and with SC-Ag-NPs (A) without SC-Ag-NPs, (B) $0.4 \mathrm{wt} \%$ of SC-Ag-NPs, (C) $0.6 \mathrm{wt} \%$ of SC-Ag-NPs, (D) $0.8 \mathrm{wt} \%$ of SC-Ag-NPs and (E) $1 \mathrm{wt} \% \mathrm{of}$ SC-Ag-NPs. (F-J) without and with SC-Au-NPs (F) Without SC-Au-NPs, (G) 0.4 wt\% of SC-Au-NPs, (H) 0.6 wt\% of SC-Au-NPs, (I) 0.8 wt $\%$ of SC-Au-NPs and (J) 1 wt $\%$ of SC-Au-NPs.

area the spreading of corrosion underneath the coating film follows the order:

$$
0.4 \% \text { Ag-NPs }>0.8 \% \text { Ag-NPs }>1 \% \text { Ag-NPs }
$$

This behavior further support the results obtained from the electrochemical measurements and the mechanism of corrosion inhibition (see 3.4).

\section{Conclusions}

In present work, SC-Ag-NPs and SC-Au-NPs have been prepared and integrated in a mixed-type inhibitors paint that was coated on carbon steel electrode. The corrosion inhibition efficiency was investigated using electrochemical techniques and salt spray test. Electrochemical measurements reveal that the corrosion potentials don't follow the same trend. However, $i_{c o r r}$ decreases in the presence of SC-NPs from 0 to $0.8 \mathrm{wt} \%$. Interestingly, when the quantity of SC-NPs exceeded $0.8 \mathrm{wt} \%$, the $i_{\text {corr }}$ increase indicating the agglomeration of NPs that convert to micron size, as a result of large specific surface area. The mechanism of the corrosion was found to be charge transfer, as evidenced manly from the Nyquist plots.

\section{Acknowledgment}

This research has been funded by scientific research deanship at University of Ha'il - Saudi Arabia through project number RG-191200.

\section{References}

[1] WG. Zhang, L. Li, SW. Yao, GQ. Zheng, Corros Sci., 2007, 49(2), 654-61.

[2] M. Gavrila, JP. Millet, H. Mazille, D. Marchandise, JM. Cuntz. Surf. Coat. Technol., 2000, 123(2-3), 164-72.

[3] M. Kraljić, Z. Mandić, L. Duić, Corros Sci., 2003, 45(1), 181-98.

[4] NM. Martyak, P. McAndrew, JE. McCaskie, J. Dijon, Prog. Org. Coat., 2002, 45(1), 23-32.

[5] AM. Fenelon, CB. Breslin, Synth Met., 2004, 144(2), 125-31. 
[6] JI. Martins, TC. Reis, M. Bazzaoui, EA. Bazzaoui, L. Martins, Corros Sci., 2004, 46 (10), 2361-81.

[7] D. Piazza, DS. Silveira, NP. Lorandi, EJ. Birriel, LC. Scienza, AJ. Zattera, Coatings., 2012, 73 (1), 42-6.

[8] N. Ichinose, Y. Ozaki, S. Kashu, Superfine particle technology. Springer Science \& Business Media, 2012.

[9] AS. Edelstein, RC. Cammaratra, editors. Nanomaterials: synthesis, properties and applications. CRC press., 1998.

[10] T. Yonezawa, H. Genda, K. Koumoto, Chem. Lett., 2003, 32(2), 194-5.

[11] CS. Kumar, M. Aghasyan, H. Modrow, E. Doomes, C. Henk, J. Hormes, J Nanopart Res., 2004, 6(4), 369-76.

[12] EM. Azzam, NG. Kandile, AM. Badawi, RM. Sami, $J$ Dispers Sci Technol., 2011, 32 (9), 1325-31.

[13] A. Labena, MA. Hegazy, WM. Kamel, A. Elkelish, WN. Hozzein, Molecules., 2020, 25(9), 2007.

[14] C. Verma, EE. Ebenso, MA. Quraishi, Green Chem., 2018.

[15] DY. Xing, WY. Dong, TS. Chung,. Ind. Eng. Chem. Res., 2016, 55(27), 7505-13.

[16] TL. Greaves, CJ. Drummond, Chem. Rev., 2015, 115(20),11379-448.

[17] V. Drioli, F. Macedonio, Ind. Eng. Chem. Res., 2012,51(30), 10051-6.

[18] AS. Amarasekara, Chem. Rev., 2016, 116(10), 6133-83.

[19] EM. Azzam, MA. Hegazy, NG. Kandil, AM. Badawi, RM. Sami, Egyptian journal of petroleum ., 2015, 24(4), 493-503.

[20] MA. Hegazy, AM. Badawi, SS. Abd El Rehim, WM.
Kamel,. Corros Sci., 2013, 69,110-22.

[21] J. Fang, C. Zhong, R. Mu, Chem. Phys. Lett., 2005, 401(1-3), 271-5.

[22] A. Šileikaite, I. Prosyčevas, J. Puišo, A. Juraitis, A. Guobienè, Mater. Sci., 2006, 12(4), 1392-20.

[23] EM. Azzam, SM. Morsy, J Surfactants Deterg., 2008, 11(3), 195-9.

[24] MA. Migahed, EM. Azzam, SM. Morsy, Corros Sci., 2009, 51(8), 1636-44.

[25] EM. Azzam, AM. Badawi, AR. Alawady, A. Soliman, $J$ Dispers Sci Technol., 2009, 30(4), 540-7.

[26] WG. Zhang, L. Li, SW. Yao, GQ. Zheng, Corros Sci., 2007,49(2), 654-61.

[27] AM. Badawi, MA. Hegazy, AA. El-Sawy, HM. Ahmed, WM. Kamel, Mater. Chem. Phys., 2010, 124(1), 458-65.

[28] AM. Atta, OE. El-Azabawy, HS. Ismail, MA. Hegazy, Corros Sci., 2011, 53(5), 1680-89.

[29] R. Rosliza, WW. Nik, HB. Senin,. Mater. Chem. Phys., 2008, 107(2-3), 281-8.

[30] JO. Bockris, Modern electrochemistry 2B: electrodics in chemistry, engineering, biology and environmental science. Springer Science \& Business Media, 1998, 2.

[31] MA. Hegazy, M.Abdallah, H. Ahmed, Corros Sci., 2010,52 (9), 2897-904.

[32] MA. Hegazy, Corros Sci., 2009, 51(11), 2610-8.

[33] MA. Quraishi, J. Rawat, Mater. Chem. Phys., 2001, 70 (1), 95-9.

[34] EE. Oguzie, Y. Li, FH. Wang, Electrochimica acta., 2007, 53(2), 909-14 